\title{
Aquaporin-1 and Endurance Performance: An Update
}

\author{
Miguel A Rivera ${ }^{1 *}$ (D) and Thomas D Fahey ${ }^{2}$ \\ ${ }^{1}$ Department of Physical Medicine, Rehabilitation \& Sports Medicine, School of Medicine, University of \\ Puerto Rico, USA \\ ${ }^{2}$ Department of Kinesiology, California State University, Chico, CA, USA
}

\section{Keywords}

Single nucleotide polymorphism, Genetics, Exercise, Genetic epidemiology

\section{Introduction}

The aquaporin-1 (AQP1) gene is associated with marathon running $(42.2 \mathrm{~km})$ performance and other phenotypes corresponding to cardiorespiratory-endurance metabolism [1-9]. Information about the molecular and biological structure and function of the AQP1 gene and the AQP1 channel is abundant [1]. Aquaporins (AQPs) are a family of integral transmembrane pore proteins classified into two subfamilies: Those which transport only water; and aquaglyceroporins that transport water and small organic compounds [2]. They are commonly known as water channels. The AQP1 channel is encoded by the AQP1 gene, on chromosome 7, region $p 14$ [3]. This gene extends 17 kilobase pairs, contains four exons and three introns [4], and displays over 150 deoxyribonucleic acids (DNA) sequence variations [5]. The AQP1 is present in various tissues, including erythrocytes, endothelial cells, smooth, skeletal, and cardiac muscle. The major AQP of the cardiovascular system is AQP1 $[6,7]$.

A recent systematic review [8] depicted studies reporting the association between the AQP1 rs1049305 ( $C>\mathrm{G}$ ) genotype and endurance (42.2 and $10 \mathrm{~km}$ ) running performance, body fluid loss in long-distance runners, along with other studies reporting on the AQP1 and cardiorespiratory endurance phenotypes associations. The first evidence asserting a link between the AQP1 Rs1049305 (C > G) genotype and marathon $(42.2 \mathrm{~km})$ running performance level was published by Martinez, et al. [9]. In a sample of Hispanic marathon runners, a higher frequency of the C-allele was observed in cases (fastest $3 \%$ ) versus controls (slowest $3 \%$ ) (Odds ratio 1.35; $95 \%$ confidence interval 1.08-1.67; $\mathrm{P}=0.005)$.

A second study evaluated the association between the AQP1 gene rs1049305 C-allele carrier status and $10 \mathrm{~km}$ running performance [10]. The findings indicated that C-allele carriers (CC and CG) ran a faster $10 \mathrm{~km}$ (approximately $37 \mathrm{~min}$ $(16.1 \mathrm{~km} / \mathrm{h})$ ) than $\mathrm{C}$ allele non-carriers (GG) (approximately $43 \mathrm{~min}(13.9 \mathrm{~km} / \mathrm{h})(\mathrm{P}<0.05)$.
The third line of evidence was an independent replication of the association between AQP1 gene sequence variant Rs1049305 ( $C>\mathrm{G}$ ) and marathon (42.2 km) running performance. During various south african ironman triathlons [11]. Triathletes carriers of the C-allele ran the $42.2 \mathrm{~km}$ stage faster (mean 286, $\mathrm{S}=49 \mathrm{~min}$ ) than those with the GG genotype (mean 296, $S=47$ min; $P=0.032$ ).

In an AQP1 gene knockout study, Xu, et al. [12], assessed A 24-h period of voluntary wheel running by Aqp1-null vs. wildtype mice in controlled environments of $16 \%, 21 \%$, and $40 \%$ $\left[\mathrm{O}_{2}\right]$. Linear regression analysis indicated that the Aqp1 knock out had lower endurance than the wild-type mice regardless of $\left[\mathrm{O}_{2}\right]$ conditions $(\mathrm{p}<0.01)$. These findings strongly suggest that knocking out the AQP1 gene in mice affected voluntary endurance exercise performance.

Fabrega, et al. [13] examined the association between the AQP1 Rs1049305 (C > G) and AQP1 expression in vitro. They observed that the G-allele was associated with reduced AQP1 expression. The same group reported that in patients with liver fibrosis, AQP1 Rs1049305 C-allele homozygotes had lower serum sodium concentration and lower serum osmolality than G-allele carriers (CG or GG). Along these lines, AQP1 null humans were unaware of any physical restrictions. However, they had limitations in fluid homeostasis in response to chronic fluid overload.

Huang and Wang [14] examined the adaptation to aero-

*Corresponding author: Miguel A Rivera, Department of Physical Medicine, Rehabilitation \& Sports Medicine, School of Medicine, University of Puerto Rico, Main Building Office A204, San Juan, PR, 00936, USA, Tel: 787-751-9625, Fax: 787-754-1471

Accepted: October 20, 2020

Published online: October 22, 2020

Citation: Rivera MA, Fahey TD (2020) Aquaporin-1 and Endurance Performance: An Update. Arch Sports Med 4(2):222-223 
bic interval training (AIT) and moderate continuous training (MCT) on osmotic stress-mediated rheological function and AQP1 channel activity of human erythrocytes under hypoxic exercise (HE) stress in humans. The findings indicated that acute HE heightened osmotic fragility and diminished deformability of erythrocytes, and depressed erythrocyte AQP1 activity as indicated by increased magnesium chloride $\left(\mathrm{HgCl}_{2}{ }^{-}\right)$ induced instability of erythrocyte membrane under hypotonic conditions. Both AIT and MCT reduced the extents of enhanced osmotic fragility, diminished deformability, and AQP1 activity of erythrocytes caused by the exercise stress.

Recently, the initial genetic association study [9] indicating that the Rs1049305 (C > G) in the 3 untranslated region of the aquaporin-1 (AQP1) gene was associated with marathon running performance in hispanic males was validated with an extra replication method [15]. A fixed effects model test of association for the combined original and replication studies revealed an odds ratio $=1.28,95 \%$ confidence interval $=1.13$ $1.45, p=0.001$. The measures of heterogeneity: Tau-squared $=0, \mathrm{H}$ statistic $=1, \mathrm{I}^{2}$ statistic $=0$, and Cochran's $\mathrm{Q}$ test $(\mathrm{Q}$ $=0.29 ; p$-value 0.59), implied the variation between studies was due to chance and not to differences in heterogeneity.

More recently, de la Iglesia, et al. [16], using a predictive algorithm of endurance performance that included the AQP1 gene Rs1049305 ( $C>G$ ) marker reported associations of this gene with endurance performance phenotypes in a sample of 15 semi-professional cyclist. The association between cardiopulmonary exercise test and AQP1 genotypes revealed that the oxygen consumption at the aerobic ventilatory threshold was lower $(P=0.020)$ in the $\mathrm{GG}$ genotype $(32.1 \pm 4.6 \mathrm{ml} / \mathrm{kg} /$ $\mathrm{min})$ than in the CC + CG $(42.3 \pm 7.4 \mathrm{ml} / \mathrm{kg} / \mathrm{min})$ genotypes. The aerobic ventilatory threshold relative to maximal oxygen uptake $\left(\mathrm{VO}_{2 \max }\right)$ was lower $(\mathrm{P}=0.030)$ in $\mathrm{GG}(58.2 \pm 7.0 \%)$ than in CC + CG (70.1 $\pm 7.7 \%)$.

In summary, Aquaporins (AQPs) are a family of integral transmembrane pore proteins that transport water and small organic compounds associated with marathon running $(42.2$ $\mathrm{km})$ performance and other phenotypes corresponding to cardio respiratory-endurance metabolism. An AQP-1 knockout study in mice showed its importance in endurance performance. In humans, distance runners with the $\mathrm{C}$ allele ran faster and had higher aerobic capacities than those with the G genotype.

\section{References}

1. The UniProt Consortium. UniProt (2020) The universal protein knowledgebase. Nucleic Acids Res 45: D158-D169.
2. Hub JS, De Groot BL (2008) Mechanism of selectivity in aquaporins and aquaglyceroporins. Proc Natl Acad Sci USA 105: 11981203.

3. Deen PMT, Weghuis DO, Geurs van Kessel A, et al. (1994) The human gene for water channel aquaporin 1 (AQP1) is localized on chromosome 7p15-p14. Cytogenet Cell Genet 65: 243-246.

4. Moon C, Preston GM, Griffin CA, et al. (1993) The human aquaporin- CHIP gene. Structure, organization, and chromosomal localization. J Biol Chem 268: 15772-15778.

5. Stelzer G, Rosen N, Plaschkes I, et al. (2019) The gene cards suite: From gene data mining to disease genome sequence analyses. Curr Protoc Bioinformatics 54: 1.30.1-1.30.33.

6. Au CG, Cooper ST, Lo HP, et al. (2004) Expression of aquaporin 1 in human cardiac and skeletal muscle. J Mol Cel Cardiol 36: 655-662.

7. Day RE, Kitchen P, Owen DS, et al. (2014) Human aquaporins: Regulators of transcellular water flow. Biochim Biophys Acta 1840: 1492-1506.

8. Rivera MA, Fahey TD (2019) Association between aquaporin-1 and endurance performance: A systematic review. Sports Med Open 5: 1-12.

9. Martínez JL, Carrión A, Florián ME, et al. (2009) Aquaporin-1 gene DNA variation predicts performance in hispanic marathon runners. Medicina Sportiva 13: 251-255.

10. Rivera MA, Martinez JL, Carrion A, et al. (2011) AQP-1 association with body fluid loss in 10-km runners. Int J Sports Med 32: 229-233.

11. Saunders CJ, Posthumus M, O'Connell K, et al. (2015) A variant within the AQP1 $3^{\prime}$-untranslated region is associated with running performance, but not weight changes, during an ironman triathlon. J Sports Sci 33: 1342-1348.

12. Xu L, Zhou Y, Courtney NA, et al. (2010) Effect of AQP1 knock out on mouse exercise tolerance. FASEB Journal 24: 609.4.

13. Fábrega E, Berja A, García-Unzueta MT, et al. (2011) Influence of aquaporin-1 gene polymorphism on water retention in liver cirrhosis. Scand J Gastroenterol 46: 1267-1274.

14. Huang YC, Wang JS (2016) Effects of interval and continuous exercise regimens on aquaporin-1-mediated osmotic fragility of erythrocyte under hypoxic stress. FASEB J 30: S1240.6.

15. Rivera MA, Fahey TD, López-Taylor JR, et al. (2020) The association of Aquaporin-1 gene with marathon running performance level: A confirmatory study conducted in male hispanic marathon runners. Sports Med Open 6: 16.

16. De la Iglesia R, Espinosa-Salinas I, Lopez-Silvarrey FJ, et al. (2020) A potential endurance algorithm prediction in the field of sports performance. Front Genet 11: 711.

DOI: $10.36959 / 987 / 256$

Copyright: (c) 2020 Rivera MA, et al. This is an open-access article distributed under the terms of the Creative Commons Attribution License, which permits unrestricted use, distribution, and reproduction in any medium, provided the original author and source are credited. 